\title{
Rotação e sucessão de culturas para o manejo do nematoide reniforme em área de produção de soja
}

\author{
Crop rotation and crop sequences for the management of the reniform \\ nematode in area of soybean production
}

\section{Hugo Márcio Leandro ${ }^{I}$ Guilherme Lafourcade AsmusII}

\section{RESUMO}

\begin{abstract}
O nematoide reniforme (Rotylenchulus reniformis) tem se tornado crescente problema fitossanitário da cultura da soja. Considerando a limitada disponibilidade de cultivares de soja que aliem resistência ao nematoide a outras características agronômicas desejáveis, estuda-se a possibilidade de utilização de manejo cultural para seu controle. Este trabalho visou avaliar o efeito da rotação de culturas no verão com milho, Crotalaria ochroleuca ou soja; e o manejo de entressafra, com Brachiaria ruziziensis como espécie de cobertura ou pousio. $O$ experimento foi implantado em solo naturalmente infestado pelo nematoide reniforme (1245 nematoides/200cc de solo) em delineamento experimental de blocos ao acaso, com quatro repetições, em esquema fatorial $3 \times 2$ (cultivos de verão $x$ manejo de entressafra). Foram avaliadas a densidade populacional do nematoide no solo e sua variação durante as safras e entressafras, bem como a produtividade da soja na safra subsequente à rotação de culturas. Não houve efeito do manejo da entressafra com braquiária sobre o nematoide. A rotação de culturas com milho ou crotalária no verão propiciou redução da densidade populacional do nematoide reniforme em comparação ao monocultivo de soja, com reflexos positivos sobre a produtividade de soja na safra seguinte.
\end{abstract}

Palavras-chave: Brachiaria ruziziensis, Crotalaria ochroleuca, entressafra, Glycine max, Rotylenchulus reniformis.

\section{ABSTRACT}

The reniform nematode (Rotylenchulus reniformis) has become a growing disease problem to soybean crop Considering the limited availability of soybean varieties that combine resistance to the nematode and other desirable agronomic traits, cultural management could be an approach for the nematode management. This study aimed to evaluate the effect of summer season crop rotations with corn or sunnhemp compared with soybean monocropping, and fall management with ruzizigrass as a covercrop compared to fallow on the nematode population. The experiment was carried-out in a naturally infested soil (1245 reniform nematodes/200cc soil) in a randomized block design, with six treatments arranged in plots with $6 \times 3 \mathrm{~m}\left(18 \mathrm{~m}^{2}\right)$ with four replications in a factorial $3 \times 2$ (summer crop $x$ fall management). The nematode soil population density and its variation during the season as well as the soybean yield in the subsequent soybean crop were evaluated. Crop rotation with corn or sunnhemp led to the decrease on the reniform nematode population density compared to the monoculture of soybeans, with positive effects on soybean yield in the following season. There was no effect of cover cropping with ruzizigrass on the reniform nematode population.

Key words: Brachiaria ruziziensis, Crotalaria ochroleuca, fall management, Glycine max, Rotylenchulus reniformis.

\section{INTRODUÇÃO}

O nematoide reniforme, Rotylenchulus reniformis Linford \& Oliveira 1940, configura-se como um dos principais nematoides fitoparasitos da cultura da soja (KINLOCH, 1998; DIAS et al., 2010). É um nematoide com ampla distribuição em regiões tropicais e subtropicais, com capacidade de parasitar centenas de espécies vegetais, boa adaptação a diferentes tipos de solos, inclusive os de textura argilosa, e alta capacidade de sobrevivência na ausência de hospedeiros (ROBINSON et al.,

IUniversidade Estadual de Mato Grosso do Sul (UEMS), Aquidauana, MS, Brasil.

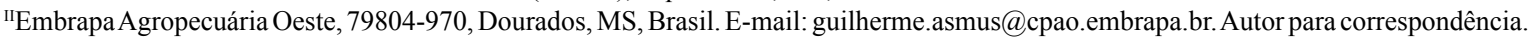
Recebido 16.04.13 Aprovado 24.10.14 Devolvido pelo autor 21.02.15 CR-2013-0526.R2 
1997; TORRES et al., 2006). Para a cultura da soja, o nematoide reniforme tem se mostrado especialmente importante em regiões produtoras dos estados do Sudeste dos EUA (KINLOCH, 1998) e do CentroSul de Mato Grosso do Sul e Sul de Mato Grosso, no Brasil (ASMUS, 2005; DIAS et al., 2010).

Embora a literatura indique que algumas cultivares de soja apresentam alta resistência ao nematoide reniforme (ROBINSON, 2002; ROBBINS et al., 2002; ROBBINS \& RAKES, 2006; ASMUS, 2008), no Brasil, são poucas as que aliam a resistência a outras características agronômicas desejáveis, tais como precocidade, resistência a glifosato e alta produtividade, de forma a serem recomendadas para cultivo (DIAS et al., 2010). Por outro lado, a densidade populacional do nematoide reniforme no solo responde de maneira consistente ao manejo cultural das áreas infestadas, observando-se sua redução com práticas de pousio ou integração lavoura-pecuária (CASWELL et al., 1991; SEREIA et al., 2007). Assim, o uso de culturas não hospedeiras em rotação ou sucessão à cultura da soja configura-se como importante possibilidade de manejo do nematoide reniforme. Experimentos realizados em áreas de produção de algodão indicam que a rotação de culturas com milho, soja resistente e capim-braquiária (DAVIS et al., 2003; ASMUS \& RICHETTI, 2010) ou o estabelecimento de culturas de cobertura, tais como sorgo forrageiro, milheto e capim-braquiária (ASMUS et al., 2008) promovem a redução da densidade populacional do nematoide no solo, com reflexos positivos sobre a produção de algodão.

A introdução de pastagens perenes nos sistemas agrícolas, como coberturas vegetais para o plantio direto ou como forrageiras em sistema integrado lavoura-pecuária, tem sido uma importante ferramenta para a diversificação de sistemas de produção agrícola. A braquiária no sistema após a colheita da soja permite seu uso como pastagem perene, por dois ou mais anos, como forrageira anual na safrinha, ou como planta de cobertura para o plantio direto (MACHADO et al., 2011).

Assim, o objetivo do presente trabalho foi avaliar o efeito de milho e crotalária, em rotação e pousio, ou capim-braquiária, em sucessão à soja, sobre a densidade populacional do nematoide reniforme, em solo naturalmente infestado.

\section{MATERIAL E MÉTODOS}

O trabalho foi conduzido em área experimental da Embrapa Agropecuária Oeste, em Dourados, MS, nas coordenadas $22^{\circ} 16^{\prime} \mathrm{S}$ e $54^{\circ} 49^{\prime} \mathrm{W}$, e $408 \mathrm{~m}$ de altitude, durante o período de novembro de 2010 a março de 2012, em um Latossolo Vermelho distroférrico, naturalmente infestado por R. reniformis (1245 nematoides/200cc de solo) e cultivado por vários anos consecutivos com soja. O delineamento experimental utilizado foi o de blocos ao acaso com quatro repetições, em esquema fatorial $3 \times 2$ (culturas de verão $\mathrm{x}$ manejo de outono/inverno), totalizando seis tratamentos (Tabela 1) dispostos em parcelas com $6 \times 3 \mathrm{~m}\left(18 \mathrm{~m}^{2}\right)$. Nos dias 11/11/2010, 15/04/2011 e $28 / 11 / 2011$, ocorreram as semeaduras das culturas do verão de 2010/2011, do outono de 2010 e verão de 2011/2012, respectivamente.

Durante a safra de verão 2010/2011, foram estabelecidos os tratamentos: milho (Zea mays L., cv. 'BRS 1010') e crotalária (Crotalaria ochroleuca L., cv. 'comum'), utilizados como culturas de rotação de verão, em comparação com o monocultivo de soja (Glycine max (L.) Merrill, cv. 'BRS 239'). Em sucessão às culturas de verão, no outono de 2011, as parcelas foram semeadas com capim-braquiária (Brachiaria ruziziensis Germain \& Everard) ou mantidas em pousio. No ano agrícola

Tabela 1 - Tratamentos para o manejo do nematoide reniforme incluindo diferentes rotações de cultura de verão e manejo de entressafra.

\begin{tabular}{lccc}
\hline Tratamento & Safra Verão 2010/2011 & Entressafra Outono 2011 & Safra \\
\hline S $-\mathrm{P}-\mathrm{S}$ & Soja & Pousio $2011 / 2012$ & Soja \\
$\mathrm{M}-\mathrm{P}-\mathrm{S}$ & Milho & Pousio & Soja \\
$\mathrm{C}-\mathrm{P}-\mathrm{S}$ & Crotalária & Pousio & Soja \\
$\mathrm{S}-\mathrm{B}-\mathrm{S}$ & Soja & Braquiária & Soja \\
$\mathrm{M}-\mathrm{B}-\mathrm{S}$ & Milho & Braquiária & Soja \\
$\mathrm{C}-\mathrm{B}-\mathrm{S}$ & Crotalária & Braquiária & Soja \\
\hline
\end{tabular}

$\mathrm{S}=$ Soja $; \mathrm{P}=$ pousio $; \mathrm{M}=$ milho $; \mathrm{C}=$ Crotalaria ochroleuca $; \mathrm{B}=$ Brachiaria ruziziensis 
2011/2012, foi semeada soja cv. 'BRS 318 RR' em todas as parcelas.

Com base em análises de solo, realizou-se adubação em todas as parcelas, aplicando-se $330 \mathrm{~kg} \mathrm{ha}^{-1}$ da fórmula 05-30-15 (NPK) de fertilizante granulado, no sulco de semeadura. Todas as semeaduras foram realizadas diretamente sobre os resíduos da cultura anterior, dessecados com herbicida $\left(2,0 \mathrm{~L} \mathrm{ha}{ }^{-1}\right.$ Glifosato Atanor ${ }^{\mathbb{R}}$ ). O espaçamento entre as linhas de plantio foi de $0,45 \mathrm{~m}$ para soja, crotalária e capimbraquiária, e de $0,90 \mathrm{~m}$ para milho. No caso de soja e milho, as populações finais por metro de plantio foram de 15 e 5 plantas, respectivamente. No caso de crotalária, foram utilizadas 30 sementes por metro e, para Brachiaria ruziziensis, $6 \mathrm{~kg} \mathrm{ha}^{-1}$ de sementes puras viáveis. Durante o período experimental, foram realizados cortes periódicos da parte aérea da forrageira, simulando pastejo, de forma que a altura das plantas fosse mantida entre $0,2 \mathrm{~m}$ e $0,4 \mathrm{~m}$. As parcelas em pousio foram manejadas quimicamente para controle de plantas daninhas.

A população de nematoides (juvenis, fêmeas imaturas e machos) no solo foi estimada em quatro épocas distintas: a) 08/11/2010, na semeadura de verão de 2010/2011 (= P1); b) 28/03/2011, na semeadura de outono/inverno de 2011 (= P2); c) 26/10/2011, na semeadura de verão de $2011 / 2012$ (= P3); e d) $02 / 03 / 2012$, no final do experimento, coincidindo com a colheita da soja da safra 2011/2012 (= P4). Para cada avaliação, foram coletadas dez subamostras de solo por parcela, com o auxílio de trado, na profundidade 0,0 a $0,20 \mathrm{~m}$, que, depois de homogeneizadas, foram embaladas em sacos plásticos, etiquetadas e acondicionadas em caixa térmica para o envio ao laboratório. Foram processados $200 \mathrm{cc}$ de cada amostra de solo para a extração dos nematoides presentes (JENKINS, 1964). Após a extração, os nematoides foram inativados em banho-maria $\left(55^{\circ} \mathrm{C} 5 \mathrm{~min}^{-1}\right)$ e mantidos em formalina (2\%). A determinação do número de nematoides (juvenis, fêmeas imaturas e machos) em alíquota de $1,0 \mathrm{~mL}$ foi realizada em lâmina de contagem de Peters, sob microscópio óptico. Dos resultados obtidos nas avaliações realizadas no início $(\mathrm{Pi})$ e final $(\mathrm{Pf}=\mathrm{P} 2$, P3 e P4) de cada ano agrícola, estimou-se a variação populacional do nematoide nas diferentes culturas durante o período experimental $(\mathrm{FR}=\mathrm{Pf} / \mathrm{Pi})$, em que FR representa o fator de reprodução do nematoide durante o período de cultivo das plantas usadas no experimento.

Adicionalmente, em 03/01/2012, foram coletadas, ao acaso, raízes de 10 plantas de soja de cada parcela, para determinação da população do nematoide nas raízes. No laboratório, as raízes foram lavadas, pesadas e processadas para a extração dos nematoides segundo COOLEN \& D'HERDE (1972). A partir da contagem do número médio de nematoides (ovos, juvenis, fêmeas imaturas e machos) por raiz e da massa da matéria fresca das raízes, foi estimado o número de nematoides por grama de raiz (NGR).

Ao final do ciclo da soja BRS cv. ' 318 RR' (12/3/2012), foram colhidos os grãos de 4,0m de três linhas centrais de todas as parcelas. Para a determinação do rendimento, foi realizada a correção da umidade para $13 \%$.

Os dados de todas as avaliações foram submetidos à análise de variância e os tratamentos comparados pelo teste de Duncan $(\mathrm{P}=0,05)$.

\section{RESULTADOS E DISCUSSÃO}

A análise da população do nematoide reniforme, no momento da instalação do experimento (P1), revelou que a área estava uniformemente infestada, com uma densidade populacional variando entre 1181 e 1285 nematoides/200cc de solo. Ao final da safra de verão 2010/2011 (P2), observouse menor densidade populacional do nematoide no solo nas parcelas cultivadas com milho ou crotalária; efeito este que se manteve durante todo o período experimental (P3 e P4), evidenciando a eficiência da rotação de culturas no manejo do nematoide (Figura 1). A análise dos dados mostrou não haver diferenças significativas $(\mathrm{P}>0,05)$ na densidade populacional entre o cultivo de capim-braquiária ou a manutenção da área em pousio, ao final do período de entressafra (P3). A variação da população (FR) durante a entressafra foi de 0,69 nas parcelas em pousio e 0,90 nas parcelas com capim-braquiária. Não foi constatada interação significativa entre os tratamentos de verão (rotação) e os tratamentos de entressafra para nenhuma das variáveis analisadas. $\mathrm{O}$ plantio de soja na safra seguinte $(2011 / 2012)$ permitiu novamente o aumento populacional do nematoide. No entanto, a densidade populacional permaneceu significativamente $(\mathrm{P}<0,05)$ inferior nas parcelas cultivadas com milho ou crotalária na safra anterior. Não houve reflexo dos cultivos de verão (soja, milho ou crotalária) e da entressafra (pousio ou cobertura com capim-braquiára) sobre o número de nematoides por unidade de raiz de soja da safra seguinte. As parcelas cultivadas com crotalária apresentaram quantidade significativamente superior de grãos de soja, quando comparadas com as demais (Tabela 2).

$\mathrm{O}$ efeito da rotação de culturas, utilizando espécies não hospedeiras, sobre a população de 


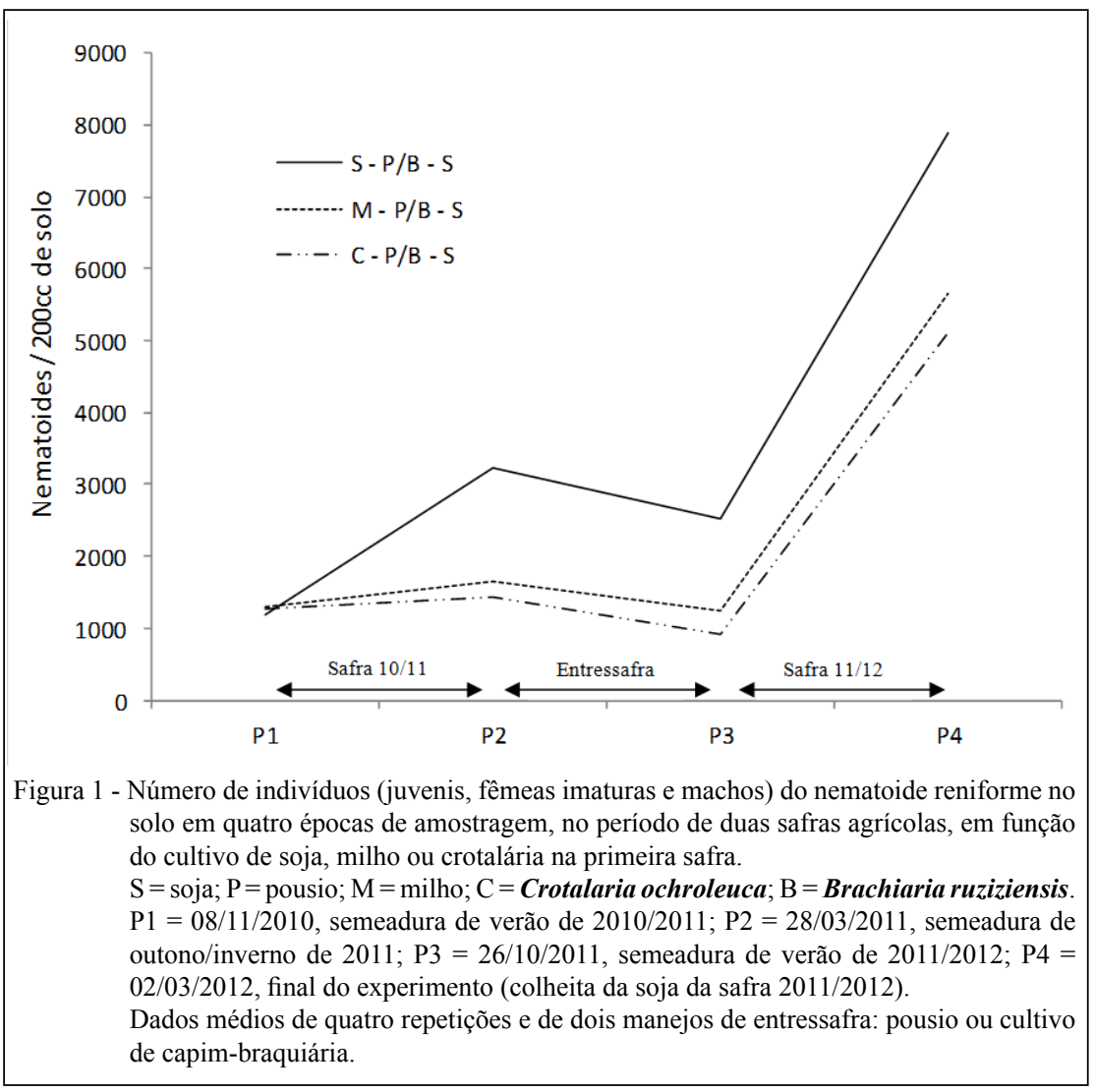

nematoides, reside, principalmente, na ausência de plantas que lhes forneçam alimento, resultando na redução da densidade populacional (NOE, 1988). Cultivares de milho e espécies de Crotalaria são más hospedeiras de $\boldsymbol{R}$. reniformis (SILVA et al., 1989; WINDHAM \& LAWRENCE, 1992). No caso de Crotalaria, outros efeitos, tais como alelopatia ou o aumento da população de fungos predadores podem exercer importante papel na redução da densidade populacional dos nematoides (INOMOTO \& ASMUS, 2014)

O efeito observado da rotação de culturas com milho sobre a população do nematoide reniforme (Figura 1) confirma a experiência anterior em área de produção de algodão, com infestação natural do nematoide reniforme semelhante a do presente experimento (949 nematoides/200cc de solo). Nesse caso, a rotação por um ou dois anos com milho reduziu a população do nematoide em aproximadamente 60 e $80 \%$, respectivamente (ASMUS \& RICHETTI, 2010). Resultados semelhantes foram obtidos por DAVIS et al. (2003), com rotação anual com milho em três diferentes locais de produção de algodão do Sudeste dos EUA. Em que pese a alta persistência do nematoide reniforme no solo e a eventual necessidade de períodos superiores a uma safra para a redução da população do nematoide, o milho pode ser considerado uma boa alternativa para rotação de culturas.

A resistência de nove espécies de Crotalaria ao nematoide reniforme em condições de casa de vegetação foi registrada por SILVA et al. (1989). Os autores não incluiram a espécie C. ochroleuca entre as testadas, no entanto, os resultados aqui apresentados sugerem que espécies desse gênero apresentam potencial para o manejo de áreas infestadas por $\boldsymbol{R}$. reniformis. No presente trabalho, $\boldsymbol{C}$. ochroleuca mostrou-se boa alternativa para a rotação de culturas, reduzindo a densidade populacional do nematoide, com reflexos sobre a produtividade da soja cultivada no ano subsequente (Figura 1 e Tabela 2).

Vale ressaltar que, embora no momento da semeadura da soja da safra 2011/2012 (P3) a densidade populacional do nematoide estivesse significativamente mais baixa nas parcelas com crotalária e milho, ainda assim estava semelhante à população observada ao início do experimento. $\mathrm{O}$ cultivo subsequente da soja suscetível, em condições climáticas favoráveis, permitiu o aumento 
Tabela 2 - Densidade populacional de Rotylenchulus reniformis por grama de raiz (NGR) e produtividade de soja (kg $\mathrm{ha}^{-1}$ ) em função de diferentes rotações de culturas.

\begin{tabular}{llc}
\hline Tratamento & NGR & Produtividade \\
\hline Soja & $129,5 \mathrm{a}$ & $1633 \mathrm{~b}$ \\
Milho & $147,0 \mathrm{a}$ & $1746 \mathrm{~b}$ \\
Crotalária & $94,0 \mathrm{a}$ & $2309 \mathrm{a}$ \\
CV $(\%)$ & 40,42 & 17,08 \\
\hline
\end{tabular}

Dados médios de quatro repetições e de dois manejos de entressafra (pousio ou cultivo de capim-braquiária).

Médias seguidas de mesma letra na coluna não diferem entre si pelo teste de Duncan $(\mathrm{P}>0,05)$.

expressivo da densidade populacional do nematoide (P4), demonstrando a necessidade de que o período de rotação fosse superior a apenas uma safra. $\mathrm{O}$ maior rendimento obtido nas parcelas onde foi cultivada crotalária na safra anterior (Tabela 2) pode ser atribuído a outros fatores que não apenas a redução da densidade populacional do nematoide. São conhecidos os efeitos de espécies de Crotalaria como fontes de nutrientes, bem como na melhoria nas condições físicas e biológicas dos solos agrícolas (SILVA et al., 2014). De todas as variáveis analisadas, a única que mostrou correlação com a produtividade da soja foi a densidade populacional do nematoide na época da semeadura $\left(\mathrm{r}=-0,43 ; \mathrm{P}=0,0170^{*}\right)$. É possível que, ao reduzir a população do nematoide a valores mais baixos dos que foram observados na P3 (época de semeadura da soja), um período maior de rotação (dois anos, por exemplo) seja necessário para a manutenção de altos níveis de produtividade da soja cultivada na sequência.

Além da presença de culturas boas hospedeiras, as condições adequadas de umidade e temperatura de solo são importantes para o desenvolvimento de nematoides edáficos. Em função disso, a densidade populacional de nematoides fitoparasitos em culturas anuais apresenta clara sazonalidade; aumentando a partir do início da estação de cultivo, quando as condições são adequadas e há disponibilidade de plantas hospedeiras, e declinando durante o outono/inverno (McSORLEY, 1998). Segundo esta lógica, as ações para conter o crescimento populacional do nematoide surtiriam maior efeito durante o cultivo de verão, fato observado no presente experimento, em que o cultivo de verão (rotação de culturas com milho ou crotalária) foi mais eficiente do que os tratamentos de entressafra, já que não houve diferença entre as densidades populacionais nas parcelas cultivadas com capim-braquiária ou em pousio.

\section{CONCLUSÃO}

A rotação de culturas com milho ou Crotalaria ochroleuca no verão propicia redução da densidade populacional do nematoide reniforme em comparação ao monocultivo de soja. Não há efeito do manejo da entressafra com Brachiaria ruziziensis sobre o nematoide reniforme se comparado com o pousio.

\section{AGRADECIMENTOS}

Os autores agradecem ao técnico de Laboratório Alex Sandro Vicentin Lima e ao técnico agrícola Mauro Rumiatto, da Embrapa Agropecuária Oeste, pelo apoio concedido na condução da pesquisa, e à Coordenação de Aperfeiçoamento de Pessoal de Nível Superior (CAPES), pela bolsa de ensino (Protocolo 00487769120) concedida ao primeiro autor.

\section{REFERÊNCIAS}

ASMUS, G.L. Evolução da ocorrência de Rotylenchulus reniformis em Mato Grosso do Sul, durante o quinquênio 2001/2005. In: REUNIÃO DE PESQUISA DE SOJA DA REGIÃO CENTRAL DO BRASIL, 27., 2005, Cornélio Procópio. Resumos... Londrina: Embrapa Soja, 2005. p.221-222. (Embrapa Soja. Documentos, 257).

ASMUS, G.L. Reação de genótipos de soja ao nematoide reniforme. Tropical Plant Pathology, v.33, n.1, p.69-71, 2008. Disponível em: <http://dx.doi.org/10.1590/S1982-56762008000100012>.

ASMUS, G.L. et al. Cover crops for reniform nematode suppression in cotton: greenhouse and field evaluations. Tropical Plant Pathology, v.33, n.2, p.85-89, 2008. Disponível em: <http:// dx.doi.org/10.1590/S1982-56762008000200001>.

ASMUS, G.L.; RICHETTI, A. Rotação de culturas para o manejo do nematoide reniforme em algodoeiro. Dourados: Embrapa Agropecuária Oeste, 2010. 26p. (Embrapa Agropecuária Oeste. Boletim de pesquisa e desenvolvimento, 55).

CASWELL, E.P. et al. Influence of nonhost plants on population decline of Rotylenchulus reniformis. Journal of Nematology, v.23, n.1, p.91-98, 1991. Disponível em: <http://www.ncbi.nlm. nih.gov/pmc/articles/PMC2619121/pdf/91.pdf>.

COOLEN, W.A.; D'HERDE, C.J.A. Method for the quantitative extraction of nematodes from plant tissue. Ghent: State Nematology and Entomology Research Station, 1972. 77p.

DAVIS, R.F. et al. Rotylenchulus reniformis management in cotton with crop rotation. Journal of Nematology, v.35, n.1, p.58-64, 2003. Disponível em: <http://www.ncbi.nlm.nih.gov/ pmc/articles/PMC2620609/pdf/58.pdf>

DIAS, W.P. et al. Nematoides. In: ALMEIDA, A.M.R.; SEIXAS, C.D.S. (Ed.). Soja: doenças radiculares e de hastes e inter-relações com o manejo do solo e da cultura. Londrina: Embrapa Soja, 2010. Cap.7, p.173-206.

Ciência Rural, v.45, n.6, jun, 2015. 
INOMOTO, M.M.; ASMUS, G.L. Adubos verdes das famílias Fabaceae e Mimosaceae para o controle de fitonematoides. In: LIMA FILHO, O.F. et al. Adubação verde e plantas de cobertura no Brasil. Brasília: Embrapa, 2014. Cap.12, p.441-479.

JENKINS, W.R. A rapid centrifugal-flotation technique for separating nematodes from soil. Plant Disease Reporter, v.48, n.9, p.692, 1964 .

KINLOCH, R.A. Soybean. In: BARKER, K.R. et al. Plant and nematode interactions. Madison: American Society of Agronomy, 1998. Cap.15, p.317-333.

MACHADO, L.A.Z. et al. Integração lavoura-pecuária-floresta 2. Identificação e implantação de forrageiras na integração lavourapecuária. Dourados: Embrapa Agropecuária Oeste, 2011. 57p. (Embrapa Agropecuária Oeste. Documentos, 111).

McSORLEY, R. Population dynamics. In: BARKER, K.R. et al. (Ed.). Plant and nematode interactions. Madison: American Society of Agronomy, 1998. Cap.6, p.109-133.

NOE, J.P. Crop- and nematode-management systems. In: BARKER, K.R. et al. (Ed.). Plant and nematode interactions. Madison: American Society of Agronomy, 1998. Cap.8, p.159-171.

ROBBINS, R.T.; RAKES, L. Resistance to the reniform nematode in selected soybean cultivars and germplasm lines. Journal of Nematology, v.28, n.4S, p.612-615, 2006. Disponivel em: <http:// www.ncbi.nlm.nih.gov/pmc/articles/PMC2619735/pdf/612.pdf $>$.

ROBBINS, R.T. et al. Host suitability of soybean cultivars and breeding lines to reniform nematodes in tests conducted in 2001 Journal of Nematology, v.34, n.4, p.378-383, 2002. Disponível em: <http://www.ncbi.nlm.nih.gov/pmc/articles/PMC2620585/ pdf/378.pdf $>$.
ROBINSON, A.F. Reniform nematodes: Rotylenchulus species. In: STARR, J.L. et al. Plant resistance to parasitic nematodes. Oxon: Cabi Publishing, 2002. Cap.7, p.153-174.

ROBINSON, A.F. et al. Rotylenchulus species: identification, distribution, host ranges, and crop plant resistance. Nematropica, v.27, n.2, p.127-180, 1997. Disponível em: <http://journals.fcla. edu/nematropica/article/view/64190/61858>.

SEREIA, A.R. et al. Influência de diferentes sistemas de produção sobre a população de Rotylenchulus reniformis (Linford \& Oliveira, 1940) no solo. Nematologia Brasileira, v.31, n.1, p.42-45, 2007. Disponível em: <http://docentes.esalq.usp.br/sbn/ nbonline/ol\%20311/42-45\%20co.pdf $>$.

SILVA, E.D. da et al. Adubação verde como fonte de nutrientes às culturas. In: LIMA FILHO, O.F. et al. Adubação verde e plantas de cobertura no Brasil. Brasília: Embrapa, 2014. Cap.6, p.265-305.

SILVA, G.S. da et al. Resistência de espécies de Crotalaria a Rotylenchulus reniformis. Nematologia Brasileira, v.13, p.8792, 1989. Disponível em: <http://docentes.esalq.usp.br/sbn/ nbonline/ol\%2013u/87-92\%20pb.pdf>.

TORRES, G.R.G. et al. Sobrevivência de Rotylenchulus reniformis em solo naturalmente infestado submetido a diferentes períodos de armazenamento. Fitopatologia Brasileira, v.31, n.2, p.203-206, 2006. Disponível em: <http://www.scielo.br/scielo. php?script $=$ sci_arttext\&pid=S0100-41582006000200015\&lng=en $\& \mathrm{nrm}=\mathrm{iso}>$.

WINDHAM, G.L.; LAWRENCE, G.W. Host status of commercial maize hybrids to Rotylenchulus reniformis. Journal of Nematology, v.24, n.4S, p.745-748, 1992. Disponível em: <http:/www.ncbi.nlm.nih.gov/pmc/articles/PMC2629870/ $\mathrm{pdf} / 745 . \mathrm{pdf}>$. 